\title{
An update on Fanconi anemia: Clinical, cytogenetic and molecular approaches (Review)
}

\author{
OLGA MARÍA MORENO ${ }^{1}$, ANGELA CAMILA PAREDES ${ }^{1,2}$, \\ FERNANDO SUAREZ-OBANDO $^{1,2}$ and ADRIANA ROJAS ${ }^{1}$ \\ ${ }^{1}$ Institute of Human Genetics, School of Medicine, Pontificia Universidad Javeriana; \\ ${ }^{2}$ Genetics Department, Hospital Universitario San Ignacio, Bogotá 110231, Colombia
}

Received February 4, 2021; Accepted June 11, 2021

DOI: $10.3892 / \mathrm{br} .2021 .1450$

\begin{abstract}
Fanconi anemia is a genetic syndrome clinically characterized by congenital malformations that affect several human systems, leads to progressive bone marrow failure and predisposes an individual to cancer, particularly in the urogenital area as well as the head and neck. It is commonly caused by the biallelic compromise of one of 22 genes involved in the FA/BRCA repair pathway in most cases. The diagnosis is based on clinical suspicion and confirmation using genetic analysis, where the chromosomal breakage test is considered the gold standard. Other diagnostic methods used include western blotting, multiplex ligation-dependent probe amplification and next-generation sequencing. This genetic condition has variable expressiveness, which makes early diagnosis difficult in certain cases. Although early diagnosis does not currently allow for improved cure rates for this condition, it does enable healthcare professionals to perform a specific systematic follow-up and, if indicated, a bone marrow transplantation that improves the mobility and mortality of affected individuals. The present review article is a theoretical revision of the pathophysiology, clinical manifestations and diagnosis methods intended for different specialists and general practitioners to improve the diagnosis of this condition.
\end{abstract}

\section{Contents}

1. Introduction

2. Clinical presentation

3. Differential diagnoses

4. Diagnostic methodologies

5. Genetic counseling

6. Other issues regarding diagnosis

7. Conclusions

Correspondence to: Professor Olga María Moreno, Institute of Human Genetics, School of Medicine, Pontificia Universidad Javeriana, Carrera 7 \#40-62, Bogotá 110231, Colombia

E-mail: moreno-o@javeriana.edu.co

Key words: Fanconi anemia, congenital anomalies, chromosomal instability, genetic counseling

\section{Introduction}

Fanconi anemia (FA) was first described in 1927 by Dr. Guido Fanconi, who observed a family of 3 siblings that presented with several physical abnormalities and pernicious anemia (Fig. 1) (1). FA is defined as a rare genetic disease of chromosomal instability that affects the proteins involved in DNA repair and the regulation of the cell cycle (2). In the majority of cases, patients with FA present with an autosomal recessive inheritance pattern, where the clinical effect is progressive depletion in bone marrow function, congenital malformations and a high risk of developing solid and hematological tumors at an earlier age than the general population (2). FA is not the same as Fanconi syndrome; the latter is a hereditary or acquired defect of the proximal tubule that leads to the malabsorption of multiple electrolytes and substances usually reabsorbed in this region (3).

FA has an incidence of 1 in 300,000 live births and a prevalence of 1-9 per million (4). The carrier frequency varies according to the populations based on the founding mutations; this is how the carrier prevalence reported in the Afrikaans population in South Africa is 1 in 83 (5), in Ashkenazi Jews is 1 in 100 (6) and in the Spanish gypsies is 1 in 64 to 1 in 70 (7), compared with the general population, where it is $\sim 1$ in 189 (8). In general, the male:female ratio of the presentation of the disease is 1.2:1 (9). This disease is a consequence, in the majority of the cases, of biallelic mutations in the 22 genes that been determined to be involved in DNA repair and genome stability, termed complementation groups FANCA-FANCW $(10,11)$. The primary inheritance pattern is autosomal recessive (genes FANCA, FANCC, FANCD1/BRCA2, FANCD2, FANCE, FANCF, FANCG/XRCC9, FANCI, FANCJ/BRIP1, FANCL, FANCM, FANCN/PALB2, FANCO/RAD5IC, FANCP/SLX4, FANCQ/ERCC4, FANCS/BRCA1, FANCT/UBE2T, FANCU/XRCC2, FANCV/REV7 and FANCW/RFWD3) (11,12), except for $F A N C B$, which exhibits X-linked recessive inheritance (13), and FANCR/RAD51, which presents a de novo autosomal dominant inheritance pattern $(14,15)$.

All proteins encoded by the aforementioned genes participate in the FA/BRCA repair pathway, which detects damage that covalently binds the two DNA strands (interstrand 


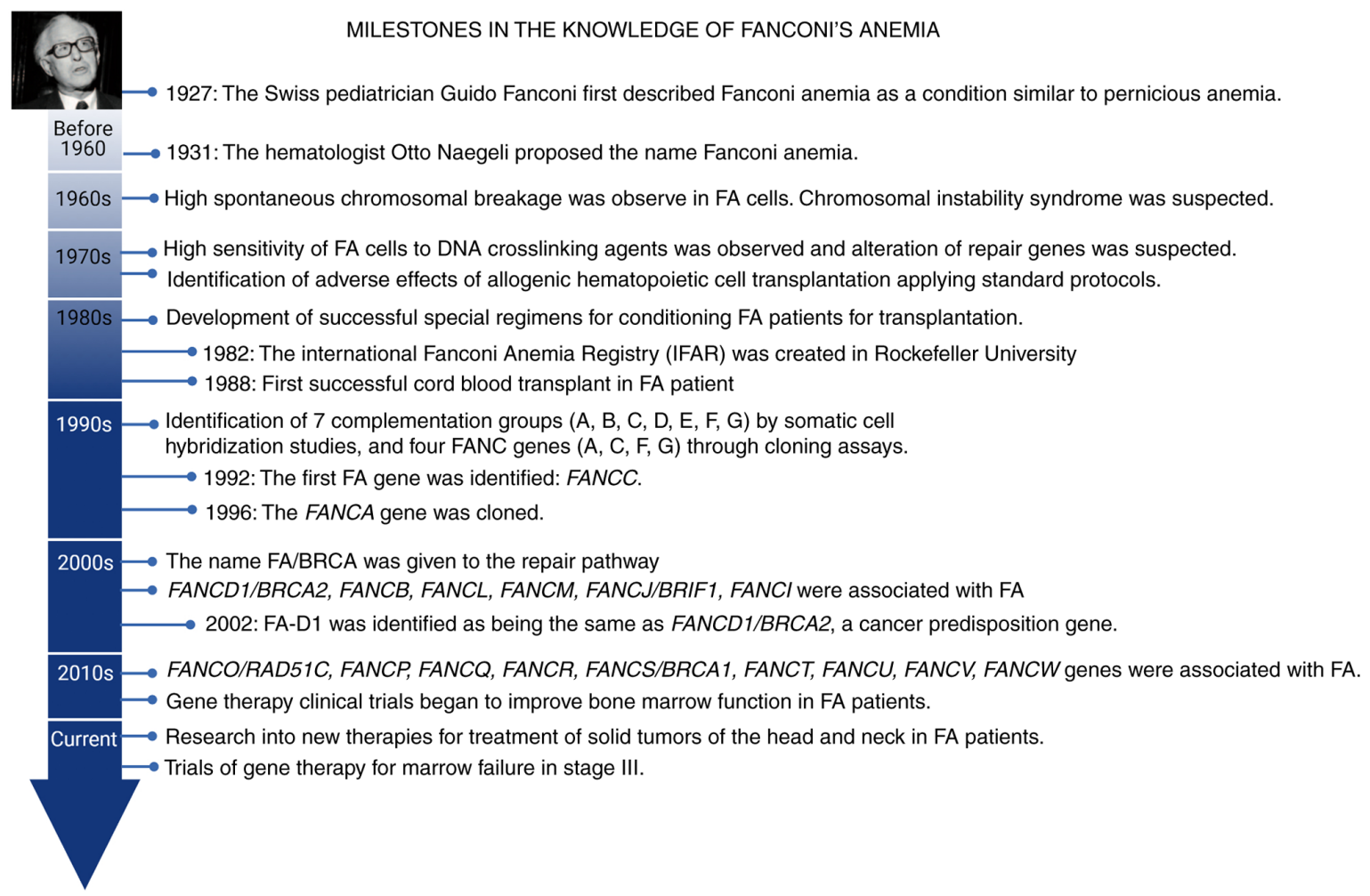

Figure 1. Principal milestones in the research and diagnosis of FA. The important events in the evolution of knowledge in the clinic, genetics and treatment of FA. Dr Guido Fanconi described FA in 1927; based on his experience, he hypothesized that patients' symptoms were very complex and could not be caused by a single genetic defect. He suggested a chromosomal alteration caused it, but this was ruled out in the 1960s. Here the search for the genetic defects responsible for the complexity of the disease begins and the development of therapies adjusted exclusively to patients with FA $(25,38,50,73-76)$. Created with BioRender. FA, Fanconi anemia.

crosslinking; ICL) and coordinates their repair through homologous monoubiquitination and recombination (16).

ICLs are formed in DNA by the presence of exogenous agents, such as cancer chemotherapeutics, as well as by endogenous agents, such as alcohol metabolites, cigarette smoke, acetaldehyde and malondialdehyde (17). These lesions cause the blockade of transcription and replication forks, making it impossible to separate double-stranded DNA; at this point, the response to DNA damage and the homologous recombination repair processes that act in the S-phase are activated (11). Individuals without compromises in this group of genes manage to eliminate ICLs; however, patients with FA do not have the optimal machinery. Unrepaired ICLs lead to DNA breakage and nonhomologous end-joining of free ends, which are visible and countable on metaphase chromosomes, in a chromosome breakage study (17). Consequently, there is an accumulation of damage in the genome, chromosomal instability, a high risk of cancer and congenital malformations in the majority of those individuals affected (16). Recently, FA proteins were discovered to fulfill other noncanonical functions in maintaining the integrity of genetic information and cellular metabolism, which explains the complexity of the FA/BRCA pathway, and its dysregulation in the etiology of the phenotype (18).

The canonical function of FANC proteins is to repair ICLs, which can be divided into three phases: i) damage recognition, AF core complex activation, and FAND2 and FANCI monoubiquitination; ii) FANCD2-FANCI complex formation; and iii) activation of the DNA repair complex and repair $(18,19)$ (Fig. 2).
In the first stage, FANCM, together with the non-AF protein FAAP24 and the DNA-binding cofactors histone-fold-containing FANCM-associated protein (MHF)1 and MHF2, recognize the lesion site (ICL) and immediately recruit FA and non-FA proteins to form the core complex (FANCA, FANCB, FANCC, FANCE, FANCF, FANCG, FANCL, FANCT/UBE2T, FAAP100 and FAAP20), which monoubiquitinates FANCD2 and FANCI (20-22). In the second stage, the FANCD2-FANCI complex or ID complex is formed, with ubiquitination that allows its displacement to the site of damage (focus formation) and the coordination of the repair of the ICL (23). Finally, in stage three, the recruitment of FA and other non-FA proteins that make DNA incisions on both sides of the ICL and unhook it (FANCP/SLX4 and FANCQ/XPF), translesion DNA synthesis (FANCV/REV7 and other non-FA proteins), and repair by homologous recombination through the formation of Holliday junction intermediaries occur for the synthesis and final replacement of double-stranded sequences of the DNA (FANCD1/BRCA2, FANCN/PALB2, FANCO/RAD51C, FANCP/SLX4, FANCQ/ERCC4, FANCR/RAD51, FANCS/BRCA1, FANCU/XRCC2, FANCV/REV7 and FANCW/RFWD3). During the S phase, the detection of ICLs leads to their repair, and proteins such as ATR-CHK1 activate the cell cycle control point to decrease the speed of DNA replication and allow repair to be finished $(16,19)$.

Early diagnosis of FA allows anticipation of possible complications and thus affects the prognosis. Early diagnosis may be based on clinical suspicions and the positive findings 


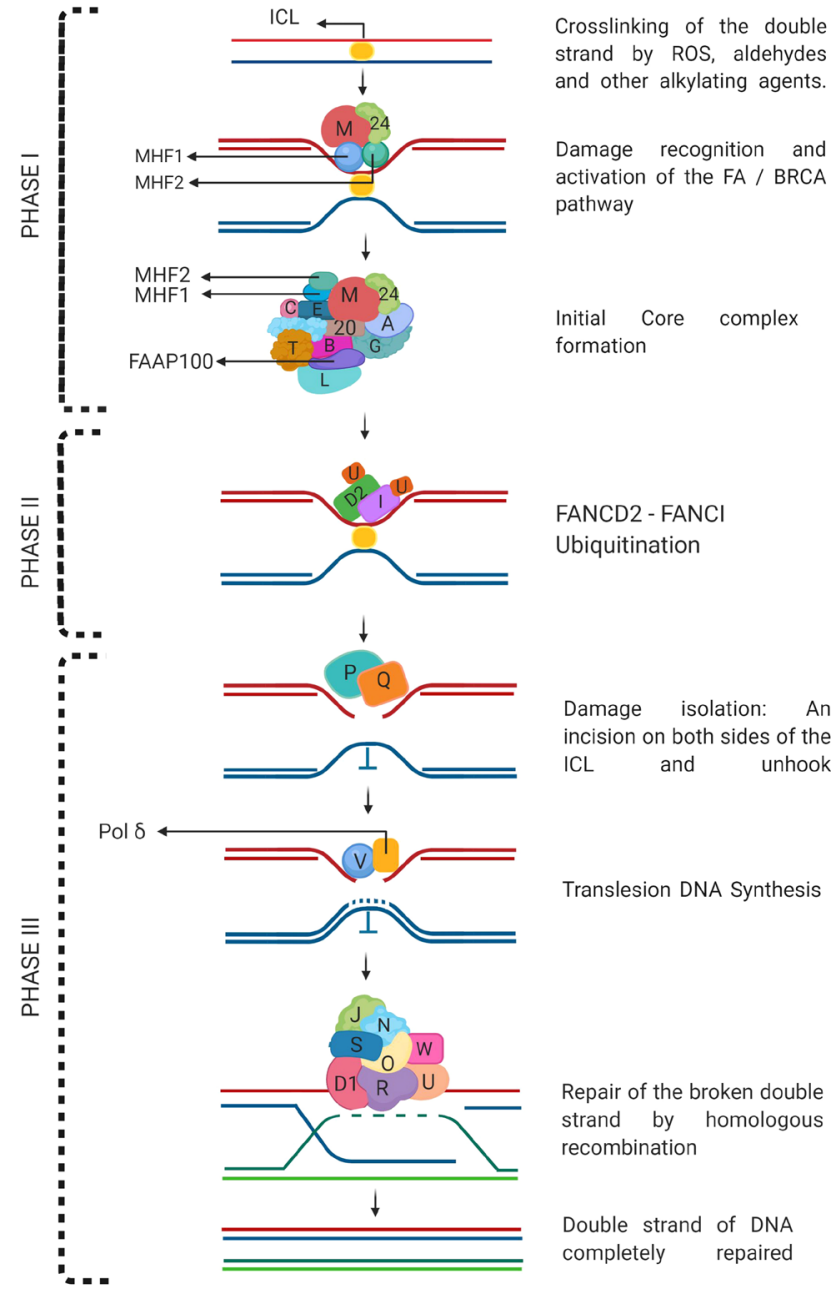

Figure 2. Schematization of the FA/BRCA repair pathway. Phase I corresponds to the recognition of ICL damage and the activation of the core complex. In phase II, the ubiquitination of FANCD2 and FANCI and their recruitment to the damage site are carried out. In phase III, the processes of ICL unhook, translesion DNA synthesis and homologous recombination occur. Capital letters identify each FANC protein, 20 and 24 are FAAP protein., Created with BioRender. FA, Fanconi anemia; ICL, interstrand crosslinking; MHF, histone-fold-containing FANCM-associated protein.

of genetic analysis, and the chromosomal breakage test is used to confirm the diagnosis; molecular tests such as western blotting, multiplex ligation-dependent probe amplification (MLPA) and gene sequencing studies using next-generation sequencing (NGS) are also used as diagnostic methods $(24,25)$. This review presents the clinical, genetic and diagnostic aspects of FA for healthcare professionals.

\section{Clinical presentation}

Patients with FA present with congenital malformations, bone marrow failure that manifests as pancytopenia, and a predisposition to cancer. Practically all systems are affected by the disease; however, the clinical presentation has a variable expressiveness (2). Not all patients present malformations or pancytopenia at birth, and the first manifestation of FA in these individuals may be solid tumors, hematologic malignancies or other complications, such as infertility $(2,26)$. Physical abnormalities are found in $75 \%$ of all patients with FA and may be accompanied by a low birth weight, short pre- and
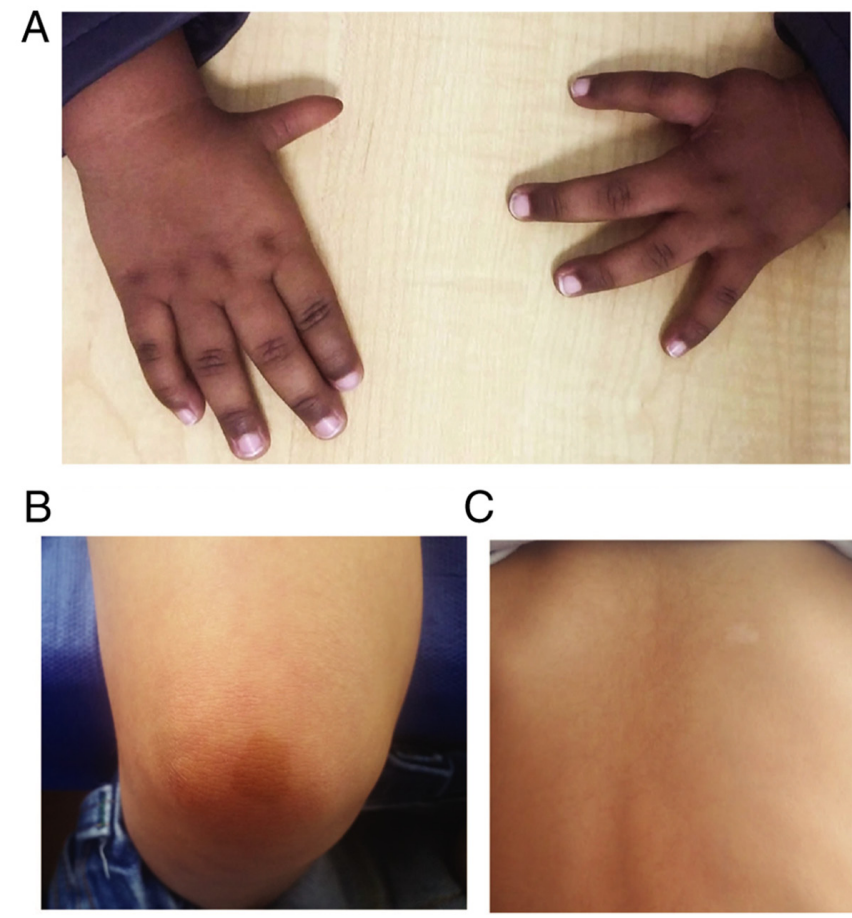

C

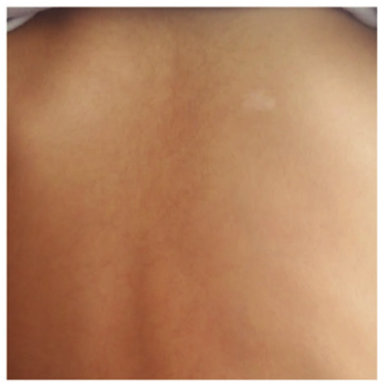

Figure 3. Phenotypic characteristics in patients with FA. (A) Typical radial ray abnormalities, bilateral thumb hypoplasia: The right hand has oligodactyly secondary to a Pollicization surgery, and the left hand has a hypoplasic thumb. (B and C) Typical skin pigmentation abnormalities: (B) Café-au-lait spot on knee. (C) Hypochromic spot on back. The photographs have come from patients analyzed at the Institute of Human Genetics, Pontificia Universidad Javeriana. FA, Fanconi anemia.

postnatal height and microcephaly $(27,28)$. The other $25 \%$ of patients represent a challenge for clinicians because the absence of physical abnormalities can delay clinical suspicion, and therefore, the timely diagnosis of the disease (29). Below are the most frequent alterations found in the different organs.

Head and neck. The face of patients with FA has particular identifiable characteristics, such as a triangular face, bilateral epicanthic folds, micrognathia and middle facial hypoplasia. Ocular findings such as microphthalmia, cataracts, astigmatism, strabismus, hypotelorism, hypertelorism and ptosis have been described $(30,31)$. The neck may be short with low implantation of the hairline, pterygium Colli, Sprengel deformity and Klippel-Feil anomaly (2).

Cardiac and gastrointestinal system. Cardiac malformations can be persistent arterial ducts, atrial or ventricular septal defects, coarctation of the aorta, common arterial trunk and situs inversus totalis (32). Only $5 \%$ of patients have gastrointestinal abnormalities such as tracheoesophageal fistula, esophageal, duodenal or jejunal atresia, imperforate anus, annular pancreas and intestinal malrotation (33).

Bone and limb defects. Limb defects are the most suggestive for diagnosis. However, limb defects are not observed in all patients, and may involve both the upper and lower extremities unilaterally or bilaterally (34). In the upper extremities, the radius, thumbs and hands (hypoplasia of the thenar and hypothenar eminence) are the most affected regions and less 
frequently, the ulna (Fig. 3A; most common malformations of the thumbs and palms of patients with FA). In the lower extremities, congenital dislocation of the hip, syndactyly and talipes have been reported (30).

In $2 \%$ of patients, spina bifida, scoliosis and abnormalities of the vertebrae (hemivertebrae, rib abnormalities, coccygeal aplasia) may be observed (2). Bone abnormalities have also been reported in the middle ear, associated with conductive hearing loss or alterations in the conformation of the auricular pavilion, which may be dysplastic or absent, low-set ears, narrow or absent internal auditory canal, absent tympanic membrane, microtia and/or fused ossicles (29).

Genitourinary system. Kidney malformations, such as horseshoe kidney, ectopic, hypoplastic, dysplastic or absence of one kidney in addition to hydronephrosis or hydroureter, have been reported in patients with FA (30). Males can present with hypospadias, micropenis, cryptorchidism, oligospermia or azoospermia, and abnormal spermatogenesis is associated with infertility (26). Females may exhibit malposition of the uterus, bicornuate uterus and smaller ovaries. Up to $50 \%$ of women are infertile, and when they achieve pregnancy, they can have complications of rapid progression, such as bone marrow failure, preeclampsia and premature delivery (29).

Endocrinological system. In the endocrinological field, $>60 \%$ of affected individuals may present with a short stature due to growth hormone deficiency, hypothyroidism, or glucose or insulin abnormalities. Due to the endocrinological abnormalities, affected individuals should be monitored with regard to their hormonal profile $(35,36)$.

Cutaneous system. The alterations described in the skin are generalized hyperpigmentation, hypopigmentation and cafe-au-lait spots (Fig. 3B; Cafe-au-lait spots and hypopigmentation in patients with FA evaluated by our FA group). The areas of hyperpigmentation are primarily on the trunk, neck, groin and armpits, with a mottled pattern of large patches and diffuse boundaries (30).

Nervous system. Malformations such as small pituitary gland, an absent corpus callosum, pituitary stalk interruption syndrome, cerebellar hypoplasia, hydrocephalus and dilated ventricles in the central nervous system have been described. Additionally, some affected individuals may present with neurodevelopmental delays and intellectual disability (33).

Hematological system. The cells of patients with FA exhibit chromosomal instability generated by the presence of unrepaired damage during the S-phase; stagnation in the $\mathrm{G} 2$ phase or passage to mitosis without adequate DNA repair has been proposed as one of the mechanisms that induces the depletion of hematopoietic cells by cellular senescence and the presence of damage that eventually leads to bone marrow failure, myelodysplastic syndrome or acute leukemia $(2,16)$.

The age of onset of bone marrow failure is very variable, even in the same family, and it rarely manifests in the lactation period. The average age of onset of hematological symptoms is 7 years (9). Bone marrow failure is one of the manifestations most commonly associated with FA, so in patients with mild or imperceptible congenital malformations, the diagnosis tends to be delayed until the onset of cytopenia (37).

Generally, at the onset of the disease, thrombocytopenia or leukopenia are present, followed by anemia in fewer cases (38). In several cases, macrocytosis and increased fetal hemoglobin are observed. As bone marrow failure advances, progression to pancytopenia occurs; therefore, patients with persistent and idiopathic FA cytopenia should be suspected (39). According to Kutler et al (40), individuals with FA have a $90 \%$ risk of developing a hematologic abnormality by the age of 40 .

Patients with FA have a high risk of developing myelodysplastic syndrome, which usually precedes acute myeloid leukemia; this condition is associated with chromosomal findings in the bone marrow, such as a gain of $3 q$, monosomy 7 or deletions in $7 \mathrm{q}(2,41)$.

As mentioned above, involvement of the hematopoietic system is the most common clinical feature in FA. The failure of the bone marrow occurs early in the life of those affected, and the median survival rate is 21 years if it is not treated early (9). Currently, the only curative treatment to restore the function of the hematological system is hematopoietic stem cell transplantation. However, this procedure requires the intervention of a trained team due to the risk of recurrence, graft-versus-host disease, and mortality (42). Recently, new treatment strategies, such as gene therapy have been implemented, in which the complications associated with hematopoietic stem cell transplantation may be avoided (38). One of these therapies uses lentiviral vectors to transfer a functional copy of a specific gene (the gene that is mutated) to autologous hematopoietic stem cells. These newly edited cells remove hematologic abnormalities in the patient and restore bone marrow cell function. The mobilization of the stem cells of the patient from the bone marrow into the peripheral blood has been proposed to collect $\mathrm{CD} 34^{+}$cells, correct the genetic alterations, and then infuse the cells into the patient (38). To date, these therapies have a good safety profile, but additional studies are required to investigate the possible long-term effects.

Solid tumors. In patients with FA, solid tumors have an accumulative incidence of $28 \%$ by the age of 40 years old $(40,43)$. Solid tumors commonly occurring in the anogenital area, and the head and neck are 500 and 700 times more frequent in patients with FA than in the healthy population, especially in cases with transplanted hematopoietic stem cells (44). Tumors in the brain, in the liver (secondary to androgen treatment) and in the kidney (as Wilms tumor) can appear as other tumors $(40,44)$. With this condition in mind, the patients should be monitored throughout a patient's life.

The most frequent carcinomas associated with FA are squamous cell carcinoma of the head and neck, preferentially located in the oral cavity, with the tongue being the most commonly affected region (45). Carcinomas appear at an earlier age than in the general population (20-40 years old) and the patients may exhibit exacerbated radiosensitivity to therapy $(46,47)$. Patients with FA have a high risk of cancer associated with human papillomavirus, which is why they should be vaccinated (48).

The defects in DNA repair in these patients makes them extremely sensitive to chemotherapy and radiotherapy; 


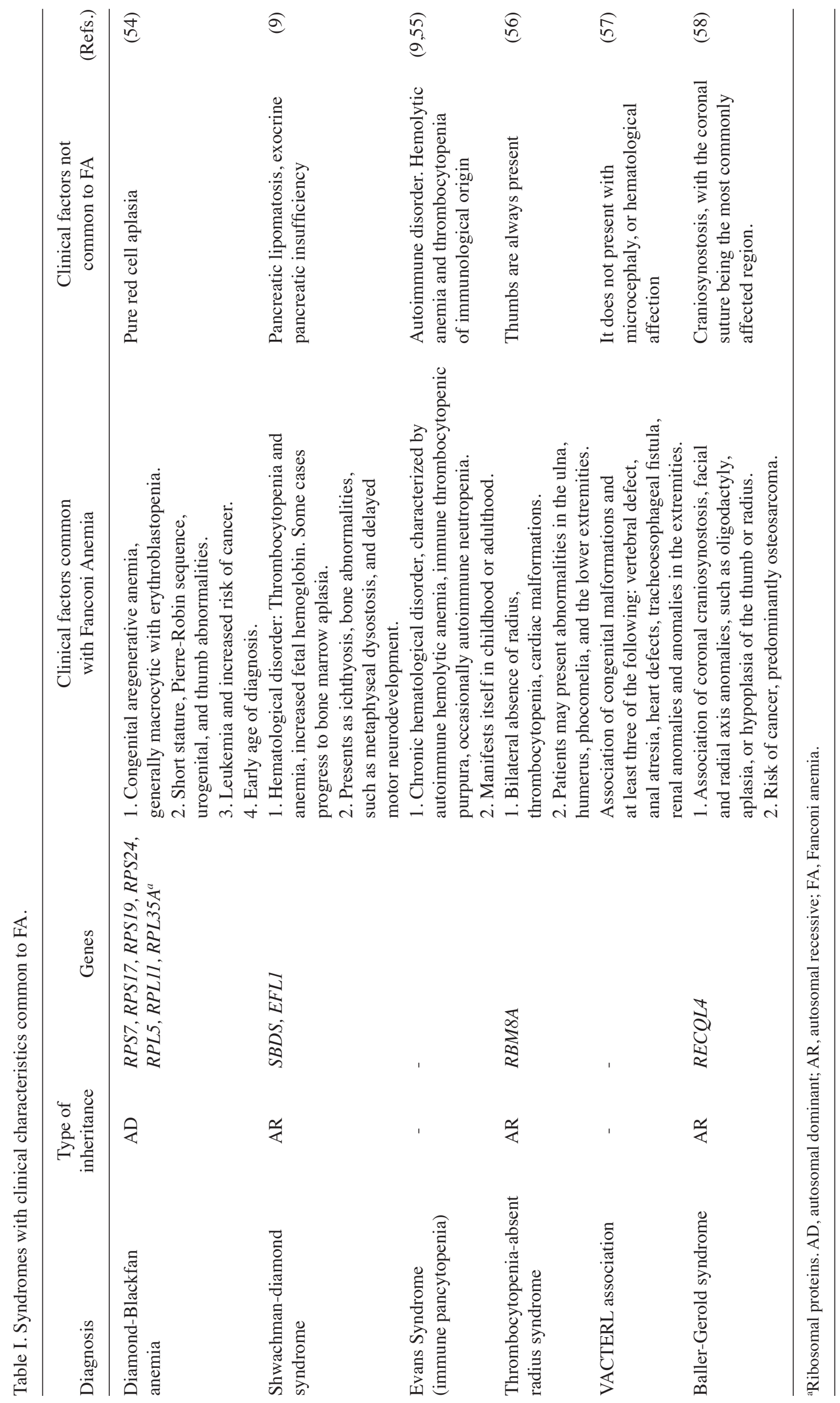


therefore, the suggested therapy is surgical resection of the tumor. However, in cases where the diagnosis is belated and large tumor sizes are encountered in surgical management, the use of radiotherapy or chemotherapy is recommended as the only scheme or in association with surgery $(43,49)$. Currently, the development of more secure and effective therapy protocols for the treatment of squamous cell tumors of the head and neck has been prioritized. Preclinical trials are being performed with drugs already approved for the treatment of cancer, with efficient cytotoxic and cytostatic activity that is nongenotoxic for the cells of patients with FA (50).

Fig. 3 presents the images of the most common alterations of 2 patients evaluated by our FA group. Fig. 3A corresponds to a 10-month-old male patient, with low height and weight at birth, bilateral thumb hypoplasia, ectopic right kidney, renal tubular acidosis, dysgenesis of the corpus callosum and colpocephaly, hypochromic spots, very brown skin and mild pancytopenia. Fig. 3B and C correspond to a 3-year-old male patient. Low height and weight, Left preaxial polydactyly, bilateral hypoplasia of thenar eminence, café-au-lait spots, hypochromic spots, mild VSD and aplastic anemia.

\section{Differential diagnoses}

As mentioned above, FA has variable expressiveness and can affect a range of systems. These characteristics overlap with several clinical manifestations of other syndromes, which often leads to a delay in an accurate diagnosis. Thus, according to the phenotype of the patient, the attending physician must consider different diagnoses.

At birth, malformations are the first signs that allow health professionals to suspect exposure to teratogens or congenital infection. Once acquired causes are ruled out, a genetic etiology must be considered. A complete systematic physical examination makes it possible to suspect a syndromic entity.

An example of differential diagnosis is esophageal atresia with or without tracheoesophageal fistula, which can be found at a low frequency in FA, and can also be related to the VACTERL association, and syndromes such as trisomy 21 and Klippel-Feil $(51,52)$. However, in the case of a patient without a history of malformations with idiopathic bone marrow insufficiency, FA or other syndromes predisposing an individual to bone marrow failure or cancer must be considered, or even syndromes that affect DNA repair genes. FA is included in inherited bone marrow failure syndrome (IBMFS), which present certain common clinical signs that make diagnosis difficult. IBMFS typically includes cytopenia of at least one hematopoietic cell lineage that can progress to pancytopenia, in addition to an elevated risk of hematologic and solid tissue cancer (53). IBMFS also includes Blackfan Diamond anemia, congenital dyskeratosis, Shwachman-Diamond syndrome, amongst other, less familiar conditions $(9,53,54-58)$. The clinical characteristics of each syndrome allow its diagnosis; however, phenotypic overlap between them frequently occurs, affecting the diagnosis and timely treatment $(9,59)$. In these cases, it is recommended to use differential diagnostic methods to confirm a diagnosis of FA (9). Table I describes the symptoms of certain conditions that are differentially diagnosed for FA. Research on these types of clinical conditions avoids incorrect or under diagnosis, and adequately determines the specific follow-up and prognosis of the affected individual.

\section{Diagnostic methodologies}

In the past, cases of FA were recognized based on the association of aplastic anemia and birth defects. However, overtime, the criteria have become more extensive, and a diagnosis is now established based on a test using hypersensitivity to clastogenic chemical agents such as diepoxybutane (DEB) or mitomycin $\mathrm{C}$ (MMC), where damage is associated with the formation of ICLs in DNA (8), or by the identification of pathogenic variants in the genes associated with FA through molecular studies. The most common tests for diagnosis are described below.

Cytogenetics. The cells of patients with FA exhibit exacerbated sensitivity to cytoreduction regimens used for bone marrow transplantation and hypersensitivity to agents that cause DNA interstrand crosslinks (60). This characteristic is the basis for the chromosome breakage test, which exposes lymphocytes or fibroblasts from individuals with suspected FA to cisplatin, $\mathrm{MMC}$ or DEB in vitro $(61,62)$.

The test consists of counting both spontaneous and induced ruptures in the metaphase chromosomes of the patients after exposure of the cells to the aforementioned agents, and comparing those ruptures with those of a healthy control individual with similar demographic characteristics. The number of chromosomal breaks per cell, the presence of radial figures, and the proportion of aberrant cells (one or more breaks/cell) are identified and recorded. A patient with FA will exhibit a significant increase in chromosomal breaks and radial figures compared with the control individual, although there may be variations in this value in patients with FA with somatic mosaicism $(62,63)$. At present, cytogenetic tests are considered the gold standard in the diagnosis of FA (64). Fig. 4 shows the different fragility expression chromosomal events that must be evaluated to establish the diagnosis of FA.

In $\sim 25 \%$ of cases of FA, patients may present with somatic mosaicism, which reduces or eliminates lymphocyte sensitivity to clastogenic agents. The presence of this condition causes difficulties in the identification of affected individuals utilizing the chromosomal breakage test (65). Somatic mosaicism in Mendelian hematopoietic disorders is the process in which one pathogenic mutation is reversed in a cell of a tissue, resulting in a group of cells with the defect corrected (66). In FA, this process occurs primarily in hematopoietic stem cells or lymphocyte progenitors. The corrected cells proliferate and clonally expand, improving the blood counts of the individual and thus reducing the incidence of bone marrow failure and hematological malignancy (67).

The cytogenetic test analyzes peripheral blood T cells; in this way, a high proportion of reversed $\mathrm{T}$ cells can lead to a false-negative result. Some individuals without FA may present with a proportion of $\mathrm{T}$ cells sensitive to DEB or MMC treatment, which could be interpreted as mosaicism, generating false positives (64). To resolve the overlap between patients with mosaic FA and non-FA patients, and to discriminate non-mosaics in patients with FA, it is proposed to use the chromosome fragility index (CFI), which calculates the quotient between the percentage of aberrant cells (cells with 1 or more 


\begin{tabular}{|c|c|c|c|c|c|}
\hline $\begin{array}{c}\text { Chromatid } \\
\text { break }\end{array}$ & $\begin{array}{c}\text { Isochromatid } \\
\text { break }\end{array}$ & $\begin{array}{c}\text { Triradial } \\
\text { chromosome }\end{array}$ & $\begin{array}{c}\text { Quadriradial } \\
\text { chromosome }\end{array}$ & $\begin{array}{c}\text { Polyradial } \\
\text { chromosome }\end{array}$ & $\begin{array}{c}\text { Ring and } \\
\text { dicentric } \\
\text { chromosomes }\end{array}$ \\
\hline 1 Break & 1 Break & 2 Breaks & 2 Breaks & 4 Breaks & $\begin{array}{c}\text { Two breaks per } \\
\text { event }\end{array}$ \\
\hline
\end{tabular}

Figure 4. Aberrant chromosomal events considered for the quantification of chromosomal breaks. The images have come from FA fragility tests of patients performed at the Institute of Human Genetics, Pontificia Universidad Javeriana.

breaks) and the number of breaks in multi-aberrant cells (cells with 2 or more breaks): [CFI = percentage of aberrant cells $\mathrm{x}$ (number of aberrations/ number of multi-aberrant cells)]; Fig. 4 shows the establishment of the number of breaks per chromosome or chromosomal event. For the Spanish population, a patient with suspected FA and a CFI $>55$ is considered to have FA, while within the group diagnosed with FA, when a patient has $<40 \%$ aberrant cells, it is considered mosaic (64). In studies of patients lymphocytes, where they have been reported as normal or inconclusive and reversal mosaicism of their bone marrow mutation, but FA is suspected, a test of sensitivity to ICL-inducing agents in fibroblasts is recommended (62).

MLPA and array comparative genomic hybridization (array-CGH). In $\sim 70 \%$ of cases of FA, the cause of the disease are pathogenic variants in the FANCA gene. Although the majority of these variants are produced by point mutations, up to $44 \%$ of cases can be caused by small deletions/insertions and large intragenic deletions. These types of variants have not only been described in the FANCA gene but also in other genes related to the disease (68).

MLPA allows the detection of intragenic deletions in FANC genes and is recommended for the initial screening of patients when the proportion of large intragenic deletions amongst mutated alleles is high, as it happens for the FANCA gene (69). This test is useful to confirm or dismiss compound heterozygosis, which explains the phenotype of the patient. Additionally, the analysis for the search for large intragenic deletions can be performed by array- $\mathrm{CGH}$, which allows establishing the extension of the deletions beyond the limits of any FANC gene, and the exact points of breakage and loss in the chromosome (68). The array-CGH test is important as the additional loss of other genes involved in the deletion may contribute to the phenotype of the patient (68).

Molecular test. With the advent of NGS, the identification of new genes associated with FA has been achieved and has allowed the analysis of several genes involved in different diseases, where clinical diagnosis is not easy. Currently, 22 genes have been confirmed to cause FA.

Within the molecular test, clinical exome sequencing or the panel of genes specifically analyzes the exons of the genes that are involved in the disease. However, despite having improved coverage and specificity, the molecular test has the disadvantage that not all panels include the same number of genes and have a low cover of intronic regions (70). Due to the above disadvantages, the specialist must ensure that the requested study contains all the genes associated with FA. For carriers or prenatal tests, the sequencing of a single gene or a specific mutation is indicated.

Once the pathogenic variant associated with FA has been identified, carriers in the family can be identified. The case of an autosomal recessive inheritance pattern will require the study of the parents to determine their carrier status and the risk to offspring. In the case of identifying a female carrier under the context of an X-linked recessive disease, the specialist should advise not only on the risks but also on the options for having healthy children, such as preimplantation diagnosis (2). In situations where the disease is considered sporadic, the patient must attend a consultation with his geneticist if they wish to have children.

\section{Genetic counseling}

Counseling is based around the inheritance pattern and the genes involved in the disease. Parental consanguinity should be questioned, as the autosomal inheritance pattern is most commonly associated with this syndrome (2).

In autosomal recessive FA, each child of a couple with a pathogenic variant has a $25 \%$ probability of inheriting both pathogenic variants and being affected, a $25 \%$ probability of inheriting both benign variants and being healthy, or $50 \%$ probability of being a carrier by inheriting a single pathogenic variant (heterozygous). When an affected individual is diagnosed with FA, there is a possibility of another asymptomatic affected individual amongst the siblings; here, cytogenetic tests should be used on all siblings to rule out the disease, as a timely diagnosis can improve the prognosis.

In autosomal dominant FA caused by a pathogenic variant in the RAD51 gene, two cases have been reported, each with a de novo variant, so the risk of having this same disease for other family members is presumed to be very low $(14,15)$. Although only 2 cases are known, the search should not be discarded, especially if clinical suspicion is high. 
Considering to whom the counseling is given in the $\mathrm{X}$-linked recessive inheritance is overriding because of the probability of transmitting the pathogenic variant changes. If genetic counseling is provided to an affected man with a healthy partner, their daughters will be carriers of the pathogenic variant, but not their sons, since they obtain the $\mathrm{Y}$ chromosome from their father. Carrier women have a $50 \%$ chance of transmitting the pathogenic variant in each pregnancy. According to this scenario, male children who inherit the pathogenic variant of the mother will be affected, whilst women will be healthy carriers.

Distinguishing heterozygous carriers from noncarriers has genetic implications, as they may have an increased risk of cancer. For example, carriers of heterozygous pathogenic variants in FANCD1/BRCA2 have an increased risk of breast and ovarian cancer (65). Knowing the pathogenic variants of the family is a priority to identify carriers or other affected members.

\section{Other issues regarding diagnosis}

FA is a rare disease, general knowledge of which is still limited. At present, for several countries in the world, including in our country of Columbia, the behavior of this disease is not known in terms of its incidence, clinical characteristics, genetics and treatment, reflecting the insufficient knowledge in the medical community that exists in the clinic, despite the existence of specialized guidelines produced by the Fanconi Anemia Research Fund (initially created in 1999, now on the fifth edition, which was published in 2020) (71), and the abundance of pertinent literature $(2,9,29,31,33,44,72)$.

In Colombia unlike in European countries, although the healthcare system allows access to cytogenetics and molecular studies, there is a significant lack of knowledge amongst healthcare professionals regarding the clinical manifestations associated with this condition. Therefore, referrals with specialists trained to diagnose orphan diseases are not prioritized. However, although the cytogenetic test is performed by several diagnostic centers, personnel trained in these types of tests are scarce, and there are no specialized reference centers for these studies in fibroblasts. Therefore, the cytogenetic group of Pontificia Universidad Javeriana in recent years has dedicated itself to investigating this disease in Colombia. In the workgroup experience with patients with FA, a delay has been observed in the diagnosis of several cases and the timely treatment of hematological complications, due primarily to the inadequate application of confirmatory cytogenetic tests for FA, confusion of the phenotype with other clinical entities, and the untimely evaluation of the patient under the clinical geneticist criteria. Thus, it is recommended that both the medical staff and the cytogenetic diagnosis should be periodically trained and updated, respectively.

\section{Conclusions}

FA is a hereditary disease in which there is a compromise of genes involved in DNA repair. When the cell cannot adequately repair its genetic information due to damage to this machinery, various clinical manifestations, such as bone marrow failure, congenital malformations and an increased predisposition to cancer occur, which increases the morbidity and mortality of these patients. Before the era of in-depth molecular studies, multiple diseases with variable expressivity could not be clinically confirmed, which limited the efforts of the professionals to improve the prognosis of affected individuals. Cytogenetic and molecular studies allowed for confirmation of diagnoses of diseases with shared symptoms and has facilitated the development of knowledge of the phenotype-genotype relationship, as well as the pathophysiology of the diseases. Both clinical and paraclinical criteria support early diagnosis, prognosis evaluation, adequate monitoring and genetic counseling for individuals and families of patients with FA.

\section{Acknowledgements}

We would like to thank Dr Jordi Surrallés of the Autonomous University of Barcelona (Spain) and to Dr Javier Benítez of the National Center for Oncological Research (CNIO; Madrid, Spain) for their academic support in the development of the FA research.

\section{Funding}

This review was partly funded by a Fanconi Anemia Grant financed by Pontificia Universidad Javeriana (Columbia; grant no. ID 00006453. Ref: 2014/150).

\section{Availability of data and materials}

Not applicable.

\section{Authors' contributions}

OMM and ACP searched the literature, reviewed the articles and collected the relevant data from selected papers. OMM, ACP, AR wrote the manuscript. ACP and FSO reviewed the clinical articles. All authors have read and approved the final manuscript. Data authentication is not applicable.

\section{Ethics approval and consent to participate}

Informed consents was signed by the parents of the patients whose images are presented (approval no. CIE-2014/150).

\section{Patient consent for publication}

Consent for publication was provided by the parents of the patients.

\section{Competing interests}

The authors declare that they have no competing interests.

\section{References}

1. Wiedemann HR: Guido Fanconi (1892-1979) in memoriam. Eur J Pediatr 132: 131-132, 1979.

2. Mehta PA and Tolar J: Fanconi Anemia. In: GeneReviews ${ }^{\circledR}$ Adam MP, Ardinger HH, Pagon RA, et al (eds). University of Washington, Seattle, WA, 2002.

3. Keefe P and Bokhari SRA: Fanconi Syndrome. In: StatPearls. StatPearls Publishing, Treasure Island, FL, 2021. 
4. Bagby GC: Multifunctional Fanconi proteins, inflammation and the Fanconi phenotype. EBioMedicine 8: 10-11, 2016.

5. Tipping AJ, Pearson T, Morgan NV, Gibson RA, Kuyt LP, Havenga C, Gluckman E, Joenje H, de Ravel T, Jansen S, et al: Molecular and genealogical evidence for a founder effect in Fanconi anemia families of the Afrikaner population of South Africa. Proc Natl Acad Sci USA 98: 5734-5739, 2001.

6. Strom CM, Crossley B, Redman JB, Quan F, Buller A, McGinniss MJ and Sun W: Molecular screening for diseases frequent in Ashkenazi Jews: Lessons learned from more than 100,000 tests performed in a commercial laboratory. Genet Med 6: 145-152, 2004

7. Callén E, Casado JA, Tischkowitz MD, Bueren JA, Creus A, Marcos R, Dasí A, Estella JM, Muñoz A, Ortega JJ, et al: A common founder mutation in FANCA underlies the world's highest prevalence of Fanconi anemia in Gypsy families from Spain. Blood 105: 1946-1949, 2005.

8. Rosenberg PS, Tamary H and Alter BP: How high are carrier frequencies of rare recessive syndromes? Contemporary estimates for Fanconi Anemia in the United States and Israel. Am J Med Genet A 155A: 1877-1883, 2011.

9. Shimamura A and Alter BP: Pathophysiology and management of inherited bone marrow failure syndromes. Blood Rev 24 $101-122,2010$

10. D'Andrea AD: The Fanconi road to cancer. Genes Dev 17: 1933-1936, 2003.

11. Niraj J, Färkkilä A and D'Andrea AD: The Fanconi Anemia Pathway in Cancer. Annu Rev Cancer Biol 3: 457-478, 2019.

12. Ceccaldi R, Sarangi P and D'Andrea AD: The Fanconi anaemia pathway: New players and new functions. Nat Rev Mol Cell Biol 17: 337-349, 2016.

13. Meetei AR, Levitus M, Xue Y, Medhurst AL, Zwaan M, Ling C, Rooimans MA, Bier P, Hoatlin M, Pals G, et al: X-linked inheritance of Fanconi anemia complementation group B. Nat Genet 36: 1219-1224, 2004.

14. Ameziane N, May P, Haitjema A, van de Vrugt HJ, van Rossum-Fikkert SE, Ristic D, Williams GJ, Balk J, Rockx D, Li H, et al: A novel Fanconi anaemia subtype associated with a dominant-negative mutation in RAD51. Nat Commun 6: 8829, 2015

15. Wang AT, Kim T, Wagner JE, Conti BA, Lach FP, Huang AL, Molina H, Sanborn EM, Zierhut H, Cornes BK, et al: A Dominant Mutation in Human RAD51 Reveals Its Function in DNA Interstrand Crosslink Repair Independent of Homologous Recombination. Mol Cell 59: 478-490, 2015.

16. Nalepa G and Clapp DW: Fanconi anaemia and cancer: An intricate relationship. Nat Rev Cancer 18: 168-185, 2018.

17. Stone MP, Cho YJ, Huang H, Kim HY, Kozekov ID, Kozekova A Wang H, Minko IG, Lloyd RS, Harris TM, et al: Interstrand DNA cross-links induced by alpha,beta-unsaturated aldehydes derived from lipid peroxidation and environmental sources. Acc Chem Res 41: 793-804, 2008.

18. Milletti G, Strocchio L, Pagliara D, Girardi K, Carta R Mastronuzzi A, Locatelli F and Nazio F: Canonical and Noncanonical Roles of Fanconi Anemia Proteins: Implications in Cancer Predisposition. Cancers (Basel) 12: 2684, 2020

19. Che R, Zhang J, Nepal M, Han B and Fei P: Multifaceted Fanconi Anemia Signaling. Trends Genet 34: 171-183, 2018.

20. Duxin JP and Walter JC: What is the DNA repair defect underlying Fanconi anemia? Curr Opin Cell Biol 37: 49-60, 2015

21. Singh TR, Saro D, Ali AM, Zheng XF, Du CH, Killen MW, Sachpatzidis A, Wahengbam K, Pierce AJ, Xiong Y, et al: MHF1-MHF2, a histone-fold-containing protein complex participates in the Fanconi anemia pathway via FANCM. Mol Cell 37: 879-886, 2010.

22. Shakeel S, Rajendra E, Alcón P, O'Reilly F, Chorev DS, Maslen S, Degliesposti G, Russo CJ, He S, Hill CH, et al: Structure of the Fanconi anaemia monoubiquitin ligase complex. Nature 575: 234-237, 2019

23. Smogorzewska A, Matsuoka S, Vinciguerra P, McDonald ER III, Hurov KE, Luo J, Ballif BA, Gygi SP, Hofmann K, D'Andrea AD, et al: Identification of the FANCI protein, a monoubiquitinated FANCD2 paralog required for DNA repair. Cell 129: 289-301, 2007.

24. Mehta PA, Davies SM, Leemhuis T, Myers K, Kernan NA, Prockop SE, Scaradavou A, O'Reilly RJ, Williams DA, Lehmann L, et al: Radiation-free, alternative-donor HCT for Fanconi anemia patients: Results from a prospective multi-institutional study. Blood 129: 2308-2315, 2017.

25. Ebens CL, MacMillan ML and Wagner JE: Hematopoietic cell transplantation in Fanconi anemia: Current evidence, challenges and recommendations. Expert Rev Hematol 10: 81-97, 2017.
26. Krausz C, Riera-Escamilla A, Chianese C, Moreno-Mendoza D, Ars E, Rajmil O, Pujol R, Bogliolo M, Blanco I, Rodríguez I, et al: From exome analysis in idiopathic azoospermia to the identification of a high-risk subgroup for occult Fanconi anemia. Genet Med 21: 189-194, 2019.

27. Freire BL, Homma TK, Funari MFA, Lerario AM, Leal AM, Velloso EDRP, Malaquias AC and Jorge AAL: Homozygous loss of function BRCA1 variant causing a Fanconi-anemia-like phenotype, a clinical report and review of previous patients. Eur J Med Genet 61: 130-133, 2018.

28. Bianchi FT, Berto GE and Di Cunto F: Impact of DNA repair and stability defects on cortical development. Cell Mol Life Sci 75 3963-3976, 2018

29. Auerbach AD: Fanconi anemia and its diagnosis. Mutat Res 668 : 4-10, 2009

30. De Kerviler E, Guermazi A, Zagdanski AM, Gluckman E and Frija J: The clinical and radiological features of Fanconi's anaemia. Clin Radiol 55: 340-345, 2000.

31. Giampietro PF, Adler-Brecher B, Verlander PC, Pavlakis SG, Davis JG and Auerbach AD: The need for more accurate and timely diagnosis in Fanconi anemia: A report from the International Fanconi Anemia Registry. Pediatrics 91: 1116-1120, 1993.

32. Tercanli S, Miny P, Siebert MS, Hösli I, Surbek DV and Holzgreve W: Fanconi anemia associated with increased nuchal translucency detected by first-trimester ultrasound. Ultrasound Obstet Gynecol 17: 160-162, 2001.

33. Schneider M, Chandler K, Tischkowitz M and Meyer S: Fanconi anaemia: Genetics, molecular biology, and cancer - implications for clinical management in children and adults. Clin Genet 88: 13-24, 2015.

34. Risitano AM, Marotta S, Calzone R, Grimaldi F and Zatterale A RIAF Contributors: Twenty years of the Italian Fanconi Anemia Registry: Where we stand and what remains to be learned. Haematologica 101: 319-327, 2016.

35. Petryk A, Kanakatti Shankar R, Giri N, Hollenberg AN, Rutter MM, Nathan B, Lodish M, Alter BP, Stratakis CA and Rose SR: Endocrine disorders in Fanconi anemia: Recommendations for screening and treatment. J Clin Endocrinol Metab 100: 803-811, 2015.

36. Rose SR, Myers KC, Rutter MM, Mueller R, Khoury JC, Mehta PA, Harris RE and Davies SM: Endocrine phenotype of children and adults with Fanconi anemia. Pediatr Blood Cancer 59: 690-696, 2012.

37. Tamary H, Nishri D, Yacobovich J, Zilber R, Dgany O, Krasnov T, Aviner S, Stepensky P, Ravel-Vilk S, Bitan M, et al: Frequency and natural history of inherited bone marrow failure syndromes: The Israeli Inherited Bone Marrow Failure Registry. Haematologica 95: 1300-1307, 2010.

38. Río P, Navarro S, Wang W, Sánchez-Domínguez R, Pujol RM, Segovia JC, Bogliolo M, Merino E, Wu N, Salgado R, et al: Successful engraftment of gene-corrected hematopoietic stem cells in non-conditioned patients with Fanconi anemia. Nat Med 25: 1396-1401,2019.

39. Rosenberg PS, Alter BP and Ebell W: Cancer risks in Fanconi anemia: Findings from the German Fanconi Anemia Registry. Haematologica 93: 511-517, 2008.

40. Kutler DI, Singh B, Satagopan J, Batish SD, Berwick M, Giampietro PF, Hanenberg H and Auerbach AD: A 20-year perspective on the International Fanconi Anemia Registry (IFAR). Blood 101: 1249-1256, 2003.

41. Savage SA and Walsh MF: Myelodysplastic Syndrome, Acute Myeloid Leukemia, and Cancer Surveillance in Fanconi Anemia. Hematol Oncol Clin North Am 32: 657-668, 2018.

42. Murillo-Sanjuán L, González-Vicent M, Argilés-Aparicio B, Badell-Serra I, Rodríguez-Villa A, Uria-Oficialdegui ML, López-Duarte M, Beléndez-Bieler C, Sastre-Urgelles A, Sevilla-Navarro J, et al: Survival and toxicity outcomes of hematopoietic stem cell transplantation for pediatric patients with Fanconi anemia: a unified multicentric national study from the Spanish Working Group for Bone Marrow Transplantation in Children. Bone Marrow Transplant 56: 1213-1216, 2021.

43. Kutler DI, Patel KR, Auerbach AD, Kennedy J, Lach FP, Sanborn E, Cohen MA, Kuhel WI and Smogorzewska A: Natural history and management of Fanconi anemia patients with head and neck cancer: A 10-year follow-up. Laryngoscope 126: 870-879, 2016.

44. Alter BP and Giri N: Thinking of VACTERL-H? Rule out Fanconi Anemia according to PHENOS. Am J Med Genet A 170: 1520-1524, 2016. 
45. Furquim CP, Pivovar A, Amenábar JM, Bonfim $\mathrm{C}$ and Torres-Pereira CC: Oral cancer in Fanconi anemia: Review of 121 cases. Crit Rev Oncol Hematol 125: 35-40, 2018.

46. Rosenberg PS, Greene MH and Alter BP: Cancer incidence in persons with Fanconi anemia. Blood 101: 822-826, 2003.

47. Bremer M, Schindler D, Gross M, Dörk T, Morlot S and Karstens JH: Fanconi's anemia and clinical radiosensitivity report on two adult patients with locally advanced solid tumors treated by radiotherapy. Strahlenther Onkol 179: 748-753, 2003.

48. Katzenellenbogen RA, Carter JJ, Stern JE, Butsch Kovacic MS, Mehta PA, Sauter SL, Galloway DA and Winer RL: Skin and mucosal human papillomavirus seroprevalence in persons with Fanconi Anemia. Clin Vaccine Immunol 22: 413-420, 2015.

49. Masserot C, Peffault de Latour R, Rocha V, Leblanc T, Rigolet A, Pascal F, Janin A, Soulier J, Gluckman E and Socié G: Head and neck squamous cell carcinoma in 13 patients with Fanconi anemia after hematopoietic stem cell transplantation. Cancer 113: 3315-3322, 2008.

50. Montanuy H, Martínez-Barriocanal Á, Antonio Casado J, Rovirosa L, Ramírez MJ, Nieto R, Carrascoso-Rubio C, Riera P, González A, Lerma E, et al: Gefitinib and Afatinib Show Potential Efficacy for Fanconi Anemia-Related Head and Neck Cancer. Clin Cancer Res 26: 3044-3057, 2020.

51. de Jong EM, Felix JF, de Klein A and Tibboel D: Etiology of esophageal atresia and tracheoesophageal fistula: 'mind the gap'. Curr Gastroenterol Rep 12: 215-222, 2010.

52. Beauregard-Lacroix E, Tardif J, Lemyre E, Kibar Z, Faure C and Campeau PM: Genetic Testing in a Cohort of Complex Esophageal Atresia. Mol Syndromol 8: 236-243, 2017.

53. Wegman-Ostrosky T and Savage SA: The genomics of inherited bone marrow failure: From mechanism to the clinic. Br J Haematol 177: 526-542, 2017.

54. Clinton $\mathrm{C}$ and Gazda HT: Diamond-Blackfan Anemia. In GeneReviews $^{\circledR}$. Adam MP, Ardinger HH, Pagon RA, et al (eds) University of Washington, Seattle, WA, 2009.

55. Shaikh H and Mewawalla P: Evans Syndrome. In: StatPearls. StatPearls Publishing, Treasure Island, FL, 2021.

56. Jameson-Lee M, Chen K, Ritchie E, Shore T, Al-Khattab O and Gergis U: Acute myeloid leukemia in a patient with thrombocytopenia with absent radii: A case report and review of the literature. Hematol Oncol Stem Cell Ther 11: 245-247, 2018.

57. Solomon BD: VACTERL/VATER Association. Orphanet J Rare Dis 6: 56, 2011.

58. Van Maldergem L, Piard J, Larizza L and Wang LL: Baller-Gerold Syndrome. In: GeneReviews ${ }^{\circledR}$. Adam MP Ardinger HH, Pagon RA, Wallace SE, Bean LJH, Mirzaa G and Amemiya A (eds). University of Washington, Seattle, WA, 2007.

59. Kallen ME, Dulau-Florea A, Wang W and Calvo KR: Acquired and germline predisposition to bone marrow failure: Diagnostic features and clinical implications. Semin Hematol 56: 69-82, 2019.

60. Gluckman E, Devergie A, Schaison G, Bussel A, Berger R, Sohier J and Bernard J: Bone marrow transplantation in Fanconi anaemia. Br J Haematol 45: 557-564, 1980.

61. Oostra AB, Nieuwint AW, Joenje H and de Winter JP: Diagnosis of fanconi anemia: Chromosomal breakage analysis. Anemia 2012: 238731, 2012.
62. Auerbach AD: Diagnosis of Fanconi anemia by diepoxybutane analysis. Curr Protoc Hum Genet 85: 8.7.1-8.7.17, 2015.

63. Esmer C, Sánchez S, Ramos S, Molina B, Frias S and Carnevale A: DEB test for Fanconi anemia detection in patients with atypical phenotypes. Am J Med Genet A 124A: 35-39, 2004.

64. Castella M, Pujol R, Callén E, Ramírez MJ, Casado JA, Talavera M, Ferro T, Muñoz A, Sevilla J, Madero L, et al: Chromosome fragility in patients with Fanconi anaemia: Diagnostic implications and clinical impact. J Med Genet 48: 242-250, 2011.

65. Fargo JH, Rochowski A, Giri N, Savage SA, Olson SB and Alter BP: Comparison of chromosome breakage in non-mosaic and mosaic patients with Fanconi anemia, relatives, and patients with other inherited bone marrow failure syndromes. Cytogenet Genome Res 144: 15-27, 2014.

66. Revy P, Kannengiesser C and Fischer A: Somatic genetic rescue in Mendelian haematopoietic diseases. Nat Rev Genet 20: 582-598, 2019.

67. Nicoletti E, Rao G, Bueren JA, Río P, Navarro S, Surrallés J, Choi G and Schwartz JD: Mosaicism in Fanconi anemia: Concise review and evaluation of published cases with focus on clinical course of blood count normalization. Ann Hematol 99: 913-924, 2020.

68. Flynn EK, Kamat A, Lach FP, Donovan FX, Kimble DC, Narisu N, Sanborn E, Boulad F, Davies SM, Gillio AP III, et al: Comprehensive analysis of pathogenic deletion variants in Fanconi anemia genes. Hum Mutat 35: 1342-1353, 2014

69. Castella M, Pujol R, Callén E, Trujillo JP, Casado JA, Gille H, Lach FP, Auerbach AD, Schindler D, Benítez J, et al: Origin, functional role, and clinical impact of Fanconi anemia FANCA mutations. Blood 117: 3759-3769, 2011.

70. Bogliolo M, Pujol R, Aza-Carmona M, Muñoz-Subirana N, Rodriguez-Santiago B, Casado JA, Rio P, Bauser C, Reina-Castillón J, Lopez-Sanchez M, et al: Optimised molecular genetic diagnostics of Fanconi anaemia by whole exome sequencing and functional studies. J Med Genet 57: 258-268, 2020.

71. Frohnmayer L, Van Ravenhorst S and Wirkkula L (eds): Fanconi anemia Clinical Care Guidelines. 5th edition. Fanconi Anemia Research Fund, Eugene, OR, 2020.

72. Rosenberg PS, Huang Y and Alter BP: Individualized risks of first adverse events in patients with Fanconi anemia. Blood 104 $350-355,2004$.

73. de Winter JP and Joenje H: The genetic and molecular basis of Fanconi anemia. Mutat Res 668: 11-19, 2009.

74. Wang X, Andreassen PR and D'Andrea AD: Functional interaction of monoubiquitinated FANCD2 and BRCA2/FANCD1 in chromatin. Mol Cell Biol 24: 5850-5862, 2004.

75. Lobitz S and Velleuer E: Guido Fanconi (1892-1979): A jack of all trades. Nat Rev Cancer 6: 893-898, 2006.

76. Sasaki MS and Tonomura A: A high susceptibility of Fanconi's anemia to chromosome breakage by DNA cross-linking agents. Cancer Res 33: 1829-1836, 1973.

This work is licensed under a Creative Commons Attribution-NonCommercial-NoDerivatives 4.0 International (CC BY-NC-ND 4.0) License. 